\section{Disaster Relief following the Earthquake in Western India: Basic Health Care Activity with ERU Operated by the Japanese Red Cross Society \\ Seishi Takamura; Akira Miyata; Sunao Asai; \\ Wakako Takasbima; Hidenobu Matsukane \\ Department of International Medical Relief, Japanese Red Cross Kumamoto Hospital}

Objective: Japanese Red Cross Society (JRCS) provided basic healthcare (BHC) activities with an emergency response unit (ERU) during the disaster relief of the western Indian earthquake on 26 January 2001. This was the first deployment of ERU operation and was the initial medical activity provided by the JRCS.

Method: The JRCS ERU team (4 doctors, 4 nurses and 4 coordinators) arrived in Bhuj near the epicenter on 30 January. The next day, a field assessment was performed, and an ERU was establish at $7 \mathrm{~km}$ from Bhuj. The ERU consisted of tents and medical equipment with a gross weight 8 tons. Medical activities were continued from 01 to 16 February, including collecting medical records, and the analysis of the data for feedback for the next phase.

Results: A total of 1,611 patients were treated during 16 days. The number of patients increased from 51 to 150 per day within a week. Twenty percent of patients were children. The ratio of earthquake-related patients was $80 \%$ in the initial phase, and gradually decreased to $10 \%$. The information collected was provided to Tokyo to help to prepare the following team, which took measures to utilize local resources, like cooperating with Indian physicians. In the later phase, though most of patients suffered internal diseases, outbreaks of acute respiratory infection and diarrhea were not observed.

Conclusion: As the variety of diseases change in post-disaster phases, it must provide appropriate disaster relief that must be adjusted to the situation.

Keywords: emergency response unit, basic health care, disaster relief, carthquake

Prehosp Disast Med 2002;17:s19.

\section{Honduras Disaster Relief Operation of Japan Self- Defense Forces in November 1998 \\ Koichi Shinchi, ${ }^{1,2}$ Eishu Nakamura, ${ }^{3}$ Hiroshi Abe; ${ }^{4}$ Hiroshi Hosoai, ${ }^{5}$ Hisayoshi Amma, ${ }^{5}$ Takashi Akima; ${ }^{5}$ Hiroomi Hashizume ${ }^{6}$}

1. Division Surgeon, The 8th Division, Japan Ground Self-Defense Force (GSDF), Japan

2. Triage Officer, Japan Medical Support Unit of Honduras International Emergency Medical Assistance Team, Japan

3. SDF Hanshin Hospital, Japan

4. SDF Fukuoka Hospital, Japan

5. SDF Central Hospital, Japan

6. National Defense Medical College, Japan

Objective: To introduce the activities of the Honduras Disaster Relief Operation of the Japan Self-Defense Forces, and to emphasize the importance of civil-military cooperation in reaponses to an international, large-scale disaster.

Disaster Scale: Between 26 October and 01 November 1998, hurricane "Mitch" swept across several Central American countries, with torrential rains and high winds causing widespread flooding and landslides. More than 6,000 people have perished, and millions more had been left homeless and without potable water.

Disaster Relief Operation: A large-scale, emergency relief program has been launched by the international community, including Japan. The Japanese Government has made a commitment to emergency medical assistance including prevention of epidemics. The authors participated in the operation as members of the Japan Medical Support Unit. The Unit consisted of 23 medical staffs including six doctors. A total 4,031 patients were examined during the two weeks of operation. Most of the patients were children and women. Honduras doctors triaged the patients first, and team members examined patients after their selection. Many aspects of civil-military cooperation were very important during this operation (e.g., translation into local languages, nursing, negotiation with Honduras Government, etc.)

Conclusion: A successful disaster relief operation was introduced in Honduras in 1998, and the importance of civil-military cooperation especially in international largescale disasters was discussed.

Keywords: Civil-Military Cooperation; Honduras; hurricane; Japan Self-Defense Forces (SDF)

Prehosp Disast Med 2002;17:s19.

Japan Disaster Relief Medical Team Activities following the Earthquake in India

Yasusbi Shimada

Emergency and Critical Care Medicine, Nippon Medical School, Japan

Objective: To review and assess the activity of the Japan Disaster Relief Medical Team, dispatched to India by the Government of Japan, through the Japan International Cooperation Agency in order to conduct relief activities for people affected by the earthquake that occurred on 26 January.

Methods: Review and investigate the present and past operations.

Results: Beginning on 01 February, two field clinics were operated at Madhapar and Kukuma. In total, 960 patients visited these clinics from 02-09 February. Traumatic injuries were the most frequently encountered medical problems $(40 \%)$. Before the clinics were established, seriously injured persons had been sent out of Buji. But, the wounds incurred from the earthquake were becoming infected. Treatment consisted of repeated irrigation and debridement of the wounds. Repetition of wound pollution resulted from their habit of walking barefoot. Treatment for their wounds could not be completed within the eight days the clinics were active. Such patients were referred to those local hospitals that had recovered from damage.

Conclusion: In spite of the limited term of operation, part 
of local sufferings were relieved. But, at the same time, there is a need for relief activities including rehabilitation. Keywords: clinics; contamination; disaster; earthquake; India; infection; relief; wounds

Prebosp Disast Med 2002;17:s19-20.

\section{Report of the Japanese Red Cross Society International Medical Relief ERU during the Earthquake in Western India \\ Koji Sato, MD; Kiyoshi Ishikawa; Nobuyuki Suzuki; \\ Mitsuki Tanaka; Kazuyoshi Yamaguchi \\ Nagoya Daini Red Cross Hospital}

Objective: The Japanese Red Cross Society (JRCS) together with the Clinic Emergency Response Unit (primary healthcare ERU), formed the International Medical Relief Team, that responded immediately to the earthquake in western India that occurred on 26 January, 2001. Methods: The team camped in Bhuj, and on 01 February, set-up the clinic $7 \mathrm{~km}$ west of this position in Sukhpur,. The clinic consisted of two tents: 1) the clinic; and 2) an operation theater. The JRCS ERU consists of 11 persons including a team leader, two doctors, four nurses, and four administrators.

Results: During this mission, 41 persons, including a doctor, a nurse, administrator, and a pharmacist, were delegated from JRCS. On average, 150 patients were treated per day, and a total of 5,000 patients were treated until the clinic was closed on 24 March.

Conclusion: Personnel training is a pressing need. The training primarily is provided by four base hospitals (Japanese Red Cross Medical Center Kumamoto Red Cross hospital, Wakayama medical center, and our hospital), and now the registration staff has increased.

Keywords: earthquake; emergency response unit; international medical relief

Prebosp Disast Med 2002;17:s20.

\section{Lessons of Earthquakes in Russia and Abroad in XXI Century}

Sergey Fedorovich Goncharov; Victor Nicholaevich

Preobrajensky

All-Russian Centre for Disaster Medicine "Zaschita"

Moscow, Russia

Objective: The unique experiences of ARCDM (Zaschita) are based on Russian and international experiences of rendering health assistance in earthquakes. At the same time, analysis of the acquired experience revealed the absence of a common international concept relating to succession and continuity of rendering different types of medical assistance. Methods: Systemic analysis of three earthquakes (Russia, Turkey, Columbia) in response activities of which ARCDM "Zaschita" took part, using methods of mathematical modeling, has been implemented.

Results: Each earthquake was characterized by different methods of rendering health assistance. In particular, in Neftegorsk (Russia), primarily evacuation procedures took place; in Izmit (Turkey), it was delivery of emergency medical care; and in Kalarka (Columbia), it included the mass delivery of outpatient care to the population.

Conclusion: Insufficient experience of rendering these types of assistance in other countries, including international standards, results in decreasing its efficiency. These lessons must be taken into consideration in the limits of forming common system of education in the field of modern problems of rendering health assistance in earthquakes. It is necessary to set up a unique international system of coordination and interaction in earthquakes based on the unique principles of healthcare delivery in such circumstances.

Keywords: earthquakes; experience; health assistance; international standards

Prehosp Disast Med 2002;17:s20.

\section{Department of International Medical Relief at Nagoya Daini Red Cross Hospital}

Mitsuki Tanaka; Kiyoshi Ishikawa, MD; Koji Sato, MD; Nobuyuki Suzuki, MD; Asako Akatsuka; Tomoko Sakai; Kazubio Komai; Tsutae Hikosaka; Kazuyoshi Yamagucbi Department of International Medical Relief, Nagoya Daini Red Cross Hospital

Objective: The domestic and international demand for the Japan Red Cross Society (JRCS) has increased. To meet this expectation, the JRCS gave an order to four Red Cross Hospitals to establish the Department of International Medical Relief (IMR).

Methods: To recruit the members, each hospital gave notice to all the hospital workers to recruit and train those who were willing to join the IMR team. Nagoya Daini Red Cross Hospital (NDRCH) voluntarily established the Department on April 2001. This document reports the preparation and the progress of this Department.

Results: After earthquake in India during January 2001, the Clinical Emergency Response Unit (JRCS primary health care ERU) was introduced and obtained excellent results. The Department of IMR in NDRCH recruits and manages the members and prepares the vaccinations for them. Also, it cooperates with the JRCS Headquarters to present the training courses. The Department carries out the study of unfamiliar diseases, and shares this knowledge with its members. It also offers English lessons to improve communication skills. Currently, there are more than 30 members.

Conclusion: Currently, IMR activities require human resources from Japan. Therefore, it is essential to have members in this hospital who contribute to this activity. Keywords: development; education; International Medical Relief Department; requirements; vaccinations

Prehosp Disast Med 2002;17:s20.

\section{Aerotransportaion and Telemedicine of the Injured Patients from Remote Volcanic Islands Makoto Mitsusada; Itaru Osaka; Nobunori Koga; \\ Tatsue Yamazaki \\ Life-Support and Emergency Center, Tokyo Metropolitan Hiroo General Hospital \\ Objective: Three large volcanic eruptions have occurred}

